\title{
Incidence and Risk Factors of Corneal Endothelial Failure after Phacoemulsification in Patients with Fuchs Endothelial Corneal Dystrophy: A I3-Year Retrospective Cohort
}

\section{Varintorn Chuckpaiwong \\ Sasin Muakkul \\ Prae Phimpho \\ Kaevalin Lekhanont \\ Passara Jongkhajornpong (D)}

Department of Ophthalmology, Faculty of Medicine, Ramathibodi Hospital, Mahidol University, Bangkok, Thailand
Correspondence: Passara Jongkhajornpong

Department of Ophthalmology, Faculty of Medicine, Ramathibodi Hospital, Mahidol

University, Ramathibodi Hospital, 270

Thanon Rama VI, Thung Phaya Thai,

Ratchathewi, Bangkok, 10400, Thailand

Tel +662-2012729

Email passaraj@yahoo.com
Objective: To evaluate the incidence of corneal endothelial failure (CEF) and determine the risk factors of developing CEF after phacoemulsification in patients with Fuchs endothelial corneal dystrophy (FECD).

Methods: A retrospective chart review of 2873 patients who underwent phacoemulsification with intraocular lens (IOL) implantation was conducted at Ramathibodi Hospital, Bangkok, Thailand from January 2007 to December 2019. Patient baseline characteristics, underlying diseases, levels of nuclear cataract, pre-operative specular microscopic parameters, intraoperative information (cumulative dissipated energy [CDE], mode of phacoemulsification, and complications), and occurrence of CEF were collected. Data were analyzed using KaplanMeier (KM) method and Cox proportional hazard model.

Results: Ninety-four patients diagnosed with FECD at follow-up time of more than 6 months were included for analysis. Mean age was $70.3 \pm 7.7$ years with female predominance $(81.91 \%)$. Median follow-up time was 3.2 years. Nine $(9.57 \%)$ patients developed CEF during follow-up period. The overall incidence rate of CEF after phacoemulsification was 26 per 1000 person years (95\% confidence interval [CI]; 14 to 49 per 1000 person years). Only intraoperative complications showed significant association with CEF at hazard ratio (HR) of 6.03 (95\% CI 1.50 to 26.50). No significant association was found among age, gender, underlying diseases, level of nuclear sclerosis and pre-operative specular microscopic parameters.

Conclusion: Intraoperative complications should be considered as an important risk factor for developing post-operative CEF in FECD patients. Apart from assessing pre-operative parameters, surgeons should also consider the possibility of and try to avoid any intraoperative complications, which could potentially result in CEF after phacoemulsification for each individual patient.

Keywords: corneal endothelial failure; CEF, phacoemulsification, Fuchs endothelial corneal dystrophy; FECD

\section{Introduction}

Fuchs endothelial corneal dystrophy (FECD) is one of the most common indications for corneal transplantation worldwide. ${ }^{1-3}$ The overall prevalence of disease ranges from $3.3-9.2 \%$ and is more frequent in females and Caucasians. ${ }^{3}$ FECD is characterized by progressive central guttae and corneal stromal edema as a result of corneal endothelial failure $(\mathrm{CEF}){ }^{3}$ Interaction between complex genetic 
susceptibility and environmental factors is considered as the main pathogenesis of the disease. ${ }^{4}$ Typically, FECD patients become symptomatic around the age of 50 and progressively worsens over time.

Cataracts are a common consequence of aging. Significant visual disturbance is the indication for performing cataract surgery. However, corneal endothelial cells can be injured after cataract extraction with phacoemulsification due to long phacoemulsification time, hard nucleus, posterior capsular rupture..$^{5-7}$ Therefore, there are additional concerns of accelerated endothelial cells loss due to cataract surgery in patients with FECD. ${ }^{8-10}$ The American Academy of Ophthalmology (AAO) Preferred Practice Pattern recommendation suggests that there is an increased likelihood of corneal failure following cataract surgery in patients with central corneal pachymetry greater than 640 microns. ${ }^{11}$ Recently, a large cohort conducted in Sweden showed that the incidence rate of corneal transplantation after phacoemulsification was as high as 68.2 times for patients with corneal guttata compared to those without (1.4 per 10,000 person years). ${ }^{12}$ Studies from Arnalich-Montiel et $\mathrm{al}^{13}$ and Patel et $\mathrm{al}^{14}$ identified preoperative corneal tomographic features from Pentacam (Oculus, Wetzlar, Germany) as predicting factors for disease progression following cataract surgery in FECD patients. However, the authors did not assess intraoperative variables that could also affect the risk.

This study aimed to evaluate the incidence rate of CEF after phacoemulsification and to identify risk factors associated with CEF in patients with FECD, considering both preoperative and intraoperative information.

\section{Methods}

A retrospective chart review of patients who underwent cataract surgery at the Cornea and Refractive Surgery Unit, Ramathibodi Hospital, Bangkok, Thailand during January, 2007 to December, 2019. This study was approved by the Ethics Committee of Ramathibodi Hospital (no. MURA2019/1007) and complied to the tenets of the Declaration of Helsinki. Patient consent to review their medical records was not required by the Ethics Committee of Ramathibodi Hospital for analysis and publication of the retrospectively obtained and anonymized data for this study.

A total of 2873 patients who underwent phacoemulsification with intraocular lens (IOL) implantation by 3 cornea specialists (VC, $\mathrm{KL}$ and $\mathrm{PJ}$ ) were reviewed. Of these patients, $176(6.12 \%)$ were diagnosed with FECD.
The diagnosis of FECD was based on the presence of guttae and disease severity was graded according to the following guidelines: grade 1: non-confluent guttae; grade 2: presence of any area of confluent guttae, but without clinical edema; grade 3: confluent guttae with clinical edema; grade 4: edema associated with whitening or haze. ${ }^{15}$ Patients with corneal pathology except FECD, previous corneal or intraocular surgery except phacoemulsification with endocapsular IOL implantation, and short follow-up time post-phacoemulsification of less than 6 months and did not develop CEF were excluded. If both eyes were eligible, only the eye with the longer follow-up time was included.

Patient baseline characteristics at preoperative period including age, gender, side, underlying disease (systemic diseases, i.e., diabetes, hypertension and ocular disease, e. g., glaucoma, age-related macular degeneration), previous ocular surgeries, ocular examination (i.e., best corrected visual acuity [BCVA], nuclear cataract grading and severity of FECD), and specular microscopic parameters (i.e., cell density $[\mathrm{CD}]$, mean cell area [MCA], coefficient of variation of cell area [CV], percentage of cell hexagonality [HEX], and central corneal thickness [CCT]) measured by Tomey EM-3000 (Tomey, Nagoya, Japan) were collected. Nuclear cataract was graded using the WHO simplified cataract grading system. ${ }^{16}$ Intraoperative information comprising of mode of phacoemulsification, cumulative dissipated energy (CDE), and intraoperative complication were obtained. CDE in conventional and torsional modes were calculated as follows; $\mathrm{CDE}$ in conventional mode $=$ average ultrasound $(\mathrm{U} / \mathrm{S})$ power $\times \mathrm{U} / \mathrm{S}$ time; $\mathrm{CDE}$ in torsional mode $=$ torsional amplitude $\times$ torsional time $\times 0.4$. Postoperative information (i.e., BVCA and specular microscopic parameters) at every follow-up visit was recorded until their last visit or until the presence of CEF. CEF was defined if a patient developed a symptomatic decrease in BCVA secondary to clinically significant corneal edema.

Surgical technique: All patients received standard technique for phacoemulsification under peribulbar anesthesia with the Infiniti/Centurion Cataract Surgery System (Alcon Laboratories, Fort Worth, Texas, USA). The main corneal incisions were created using a $3 \mathrm{~mm}$ keratome at temporal side. A $1.2 \mathrm{~mm}$ incision was done using a microblade for the side port. Then, the anterior chamber was filled with Viscoat (3\% sodium hyaluronate, $4 \%$ chondroitin sulfate, Alcon Laboratories) and continuous curvilinear capsulorhexis (CCC) was performed with 
a capsulorhexis forceps. Lens segmentation was performed using a stop and chop approach, followed by lens cortex removal. Finally, IOLs were implanted in the capsular bag. At postoperative period, prednisolone acetate 1\% (8 times a day) and topical antibiotics (4 times a day) were prescribed during the first week and tapered off over the next 3 weeks. Hypertonic saline (3\% sodium chloride) 4 times a day was added in individuals with postoperative corneal edema.

Statistical analyses were performed using STATA Software version 16.0 (Stata Corp, College Station, TX, USA). Quantitative data were described in mean (standard deviation; SD) or median (interquartile range; IQR). A Kaplan-Meier (KM) survival analysis was conducted to demonstrate the survival of corneal endothelium overtime and estimate survival probability for each time interval. To identify risk factors associated with CEF, Cox proportional hazards regression was applied for all preoperative/intraoperative variables. HR and $95 \% \mathrm{CI}$ of each factor was estimated. All analyses were two-tailed with a type I error level at 0.05 .

\section{Results}

Of the 176 patients with FECD who underwent phacoemulsification in our center, 94 patients (94 eyes) were eligible and included into the analysis. Nine patients were excluded due to short follow-up time of less than 6 months. Their baseline characteristics and clinical information were provided in the Supplementary File. Most patients were female (77 patients, $81.91 \%$ ) with the mean age of $70.3 \pm 7.7$ years. All baseline characteristics, preoperative ocular examination, severity of disease and specular microscopy, and intraoperative information are presented in Table 1. Median follow-up time after phacoemulsification was 3.2 (IQR 1.6-5.9) years. Nine patients $(9.57 \%)$ experienced the outcome of CEF. From a total time at risk of 356.2 years, the overall incidence rate of CEF among patients with FECD after phacoemulsification was 26 per 1000 person years (95\% CI; 14 to 49 per 1000 person years). Median survival time was estimated at over 12.5 years. KM curve with numbers of patients at risk and CEF events at each time point is shown in Figure 1.

From Cox proportional hazard regression, we did not observe a significant association between preoperative variables (i.e., gender, age, underlying disease, severity of disease, specular microscopic parameters, and nuclear sclerosis grading) and the presence of CEF. There was
Table I Patient Characteristics and Intraoperative Information $(\mathrm{N}=94)$

\begin{tabular}{|c|c|}
\hline $\begin{array}{l}\text { Characteristics and Intraoperative } \\
\text { Information }\end{array}$ & $\mathbf{N}(\%)$ \\
\hline \multicolumn{2}{|l|}{ Gender } \\
\hline Male & 17 (18.09\%) \\
\hline Female & 77 (81.91\%) \\
\hline Age, mean (years) & 70.30 (SD 7.70) \\
\hline$\leq 70$ years & $47(50 \%)$ \\
\hline$>70$ years & $47(50 \%)$ \\
\hline Glaucoma & 14 (14.89\%) \\
\hline Diabetes & $21(22.34 \%)$ \\
\hline BCVA (LogMAR), median & 0.40 (IQR $0.30,0.52)$ \\
\hline \multicolumn{2}{|l|}{ Severity of disease } \\
\hline Grade 1 & $32(34.04 \%)$ \\
\hline Grade 2 & $62(65.96 \%)$ \\
\hline \multicolumn{2}{|l|}{ Specular microscopy } \\
\hline Cell count (cells), median & 7I (IQR 27, 129) \\
\hline Central corneal thickness $(\mathrm{CCT}, \mu \mathrm{m})$, mean & $532(S D 43)$ \\
\hline Endothelial cell density $\left(E C D\right.$, cells $\left./ \mathrm{mm}^{2}\right)$, mean & 2221 (SD 514) \\
\hline Mean cell area $\left(\mathrm{MCA}, \mu \mathrm{m}^{2}\right)$, median & 444 (IQR 384, 538) \\
\hline Hexagonal endothelial cell ratio (\%), median & $24(\mathrm{IQR} 7,34)$ \\
\hline Coefficient of value (CV), mean & 48.77 (SD 13.46) \\
\hline \multicolumn{2}{|l|}{ Nuclear sclerosis level } \\
\hline Level I-2 & $71(75.53 \%)$ \\
\hline Level 3-4 & $23(24.47 \%)$ \\
\hline Cumulative dissipated energy (CDE), median & 15.40 (IQR 8.64, 26.18) \\
\hline $\mathrm{CDE} \leq 25$ & $63(74.12 \%)$ \\
\hline $\mathrm{CDE}>25$ & $22(25.88 \%)$ \\
\hline \multicolumn{2}{|l|}{ Mode of phacoemulsification } \\
\hline Conventional mode & $66(70.21 \%)$ \\
\hline Torsional mode & $28(29.79 \%)$ \\
\hline Intra-operative complications & 7 (7.45\%) \\
\hline Descemet detachment & $4(4.25 \%)$ \\
\hline Corneal edema & $2(2.13 \%)$ \\
\hline Iris incarceration & I (1.06\%) \\
\hline
\end{tabular}

Abbreviations: IQR, interquartile range; SD, standard deviation.

a trend of increased risk for CEF in patients with male gender, aged over 70 years, higher disease severity, higher nuclear sclerosis level, and poor pre-operative specular parameters (i.e., ECD $<1500$ cells $/ \mathrm{mm}^{2}$, MCA $>500$ $\mu \mathrm{m}^{2}, \mathrm{HEX}<20 \%$, and $\mathrm{CV}>50 \%$ ), but not statistically significant. Among 3 intraoperative factors, only intraoperative complication showed significant association with $\mathrm{CEF}$ at HR of 6.03 (95\% CI 1.50 to $26.50, \mathrm{p}=0.012$ ) shown in Table 2. Seven eyes experienced intraoperative complications including Descemet's membrane detachment (DMD; 4 eyes, 4.25\%), intraoperative corneal 


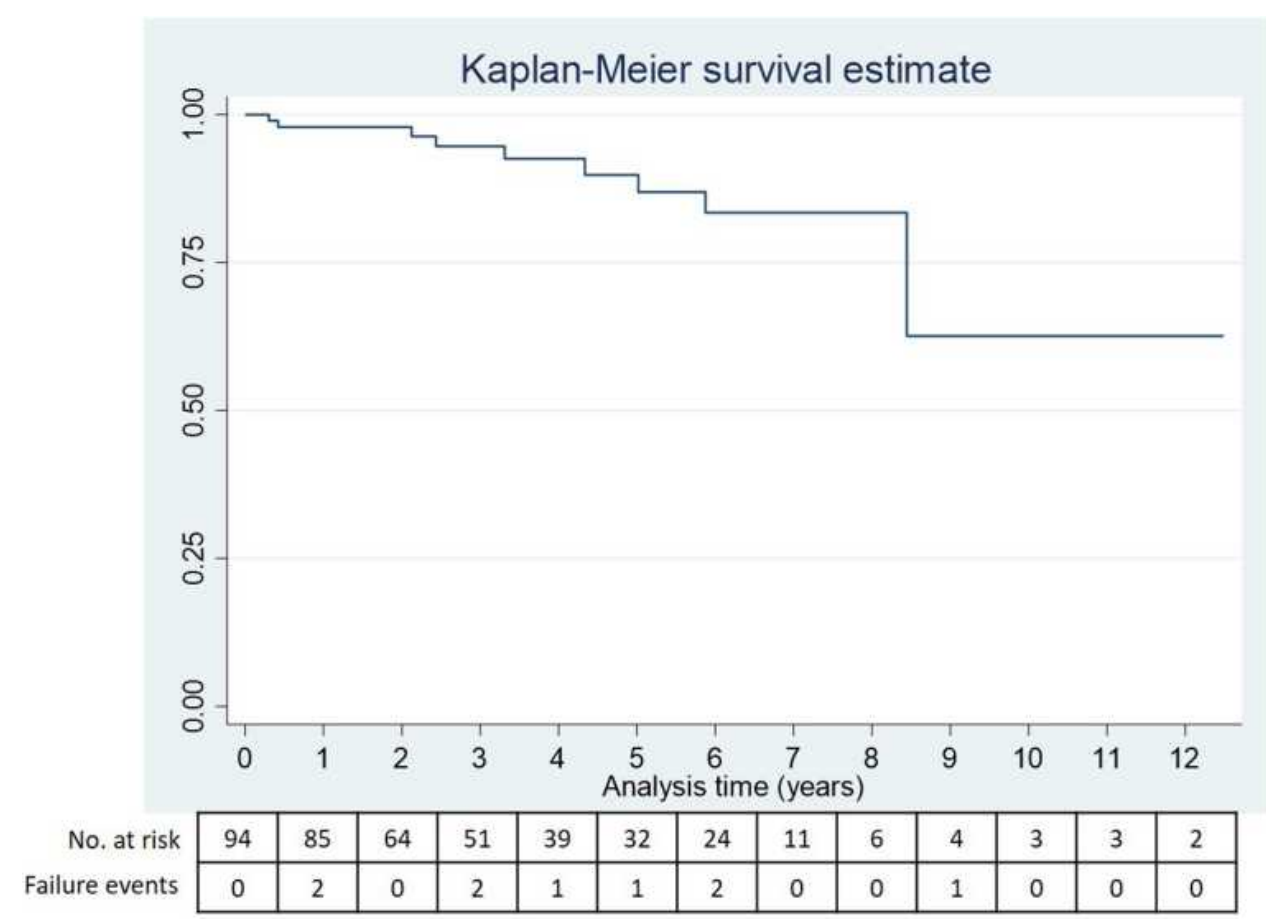

Figure I KM survival curve for corneal endothelial survival in patients with FECD after phacoemulsification.

edema ( 2 eyes, $2.13 \%)$ and iris incarceration ( 1 eye, $1.06 \%$ ). Interestingly, none of the patients who underwent phacoemulsification with torsional mode developed CEF. As only one factor was found significant from univariate analysis, multivariate analysis was not performed.

\section{Discussion}

FECD is not uncommonly found in patients who undergo cataract surgery. This current study showed that approximately $6.12 \%$ of phacoemulsification in our center was performed in FECD patients. This prevalence is in range with the global prevalence (3.3\% to $9.2 \%)$. Previously, cataract surgery was considered as one important risk factors for performing earlier penetrating keratoplasty in patients with FECD. ${ }^{17} \mathrm{Kim}$ et al demonstrated that the annual endothelial cell loss after undergoing phacoemulsification in Asian eyes with FECD was $20.39 \%$ per year compared to $0.82 \%$ per year in patients with no surgery. ${ }^{9}$ However, the authors did not observe exponential changes after cataract surgery and preferred the cataract surgery approach rather than "wait-and-do" simultaneous penetrating keratoplasty and cataract surgery. ${ }^{9}$

Given the improvement in modern phacoemulsification techniques from the AAO guideline ${ }^{18}$ and based on the results from Seitzman et al, the authors recommend that all eyes with $\mathrm{CCT} \leq 640$ microns can proceed with cataract surgery alone. ${ }^{19}$ It should be noted that pachymetry values can vary with gender and age, and differ between ethnic groups as well as measurement techniques. ${ }^{20,21}$ Therefore, to apply this extended criteria in different clinical settings should be considered with caution. Although, all patients in our cohort had pre-operative CCT values that complied with the guideline, we found that $9(9.57 \%)$ patients eventually developed CEF within the 10 years of follow-up period, corresponding to the incidence rate of 26 per 1000 person years. A registry-based cohort study in the Swedish between 2010 to 2012 found that the overall incidence rate of corneal transplantation after phacoemulsification among patients with guttata was 9 per 1000 person years. ${ }^{12}$ The incidence rate of CEF in our study is approximately 3 times compared to Swedish registry. Different ethnicities, patient characteristics, time frames and outcome definitions (CEF vs. corneal transplantation) could possibly explain the dissimilar results.

Our study pointed out the importance of intraoperative complication, which was significantly associated with the development of CEF in patients with FECD. We also considered all available pre-operative factors including gender, age, underlying disease of diabetes and glaucoma, specular microscopic parameters, and level of nuclear sclerosis, and phacoemulsification parameters (i.e., CDE and mode of phacoemulsification). However, these 
Table 2 Factors Associated with Endothelial Failure After Cataract Surgery in Patients with FECD

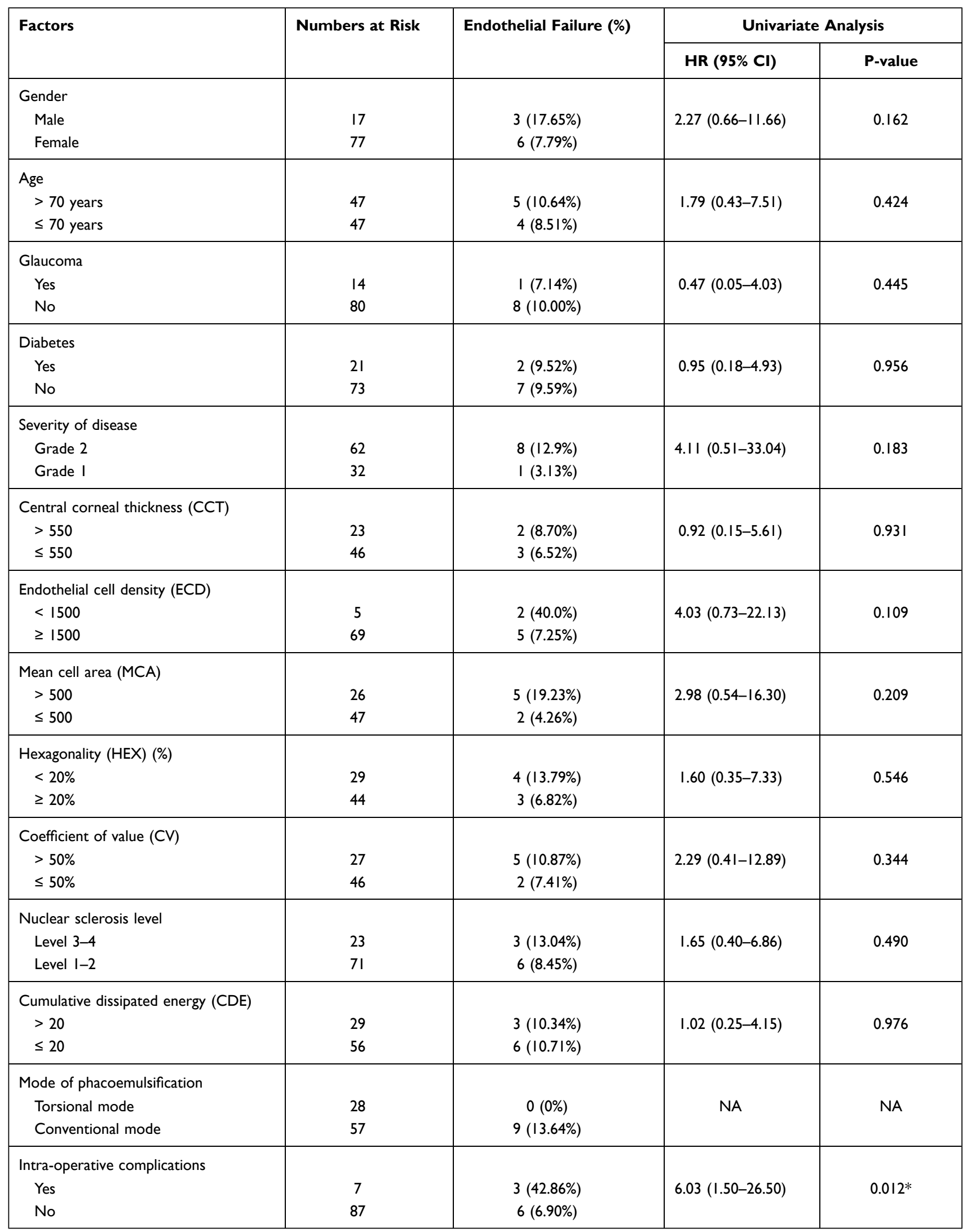

Notes: *Statistical significance at P-value $<0.05$. The adjusted HR by gender and endothelial cell density was $5.09(95 \% \mathrm{Cl} 1.20,21.59)$ with an adjusted P-value of 0.027 . Abbreviations: $\mathrm{Cl}$, confidence interval; $\mathrm{HR}$, hazard ratio. 
parameters did not show a significant association with CEF. The recent evidence has revealed that backscatter of the cornea at basal epithelial cell layer measured by in vivo confocal microscopy (IVCM) ${ }^{22}$ and anterior layer cornea measured by Pentacam are good predictors for indicating patients who are at risk for corneal transplantation. ${ }^{13,14}$ It should be noted that intraoperative variables that could affect the risk of proceeding to corneal transplantation was not considered in those studies. Additionally, IVCM and corneal topography might not always be available in general cataract centers, resulting in a limitation of their application in clinical practice.

In terms of intraoperative factors, we observed that none of the patients using torsional mode experienced $\mathrm{CEF}$. A torsional emulsification mode of phacoemulsification produces rotary oscillations, contrary to the forward-backward movement of the tip in conventional longitudinal phacoemulsification, ${ }^{23}$ which might reduce the amount of energy during phacoemulsification and cause less trauma to the corneal endothelium. ${ }^{24} \mathrm{CDE}$ of higher than 20 slightly increased the risk of CEF, however, there was no statistical significance. We found that patients with intra-operative complications including DMD, iris incarceration and intraoperative corneal edema were about 6 times more likely to develop CEF compared to those without intraoperative complications. DMD is a potential vision-threatening complication after cataract surgery, especially in patients with preexisting endothelial abnormalities. ${ }^{25}$ Various mechanical injuries have been considered in the pathogenesis of DMD consisting of blunt microkeratome, inappropriate corneal incision, inadvertent trauma during viscoelastic/saline injection and IOL insertion. ${ }^{26}$ Similarly, iris incarceration also requires repeated manipulation at the main corneal incision due to inserting the instrument in and out of the anterior chamber, which might also result in escalated endothelial cell damage. Intra-operative corneal edema might possibly indicate very poor pumping function of corneal endothelial cells and reflect the higher risk of developing CEF in the future.

This study has some limitations due to the nature of its retrospective design. Corneal backscatter data from Pentacam or confocal scanning were not available for analysis. All surgeries in this cohort were operated on by 3 experienced cornea specialists in a university hospital setting. This might positively bias and limit the generalizability of the post-operative outcomes of this cohort. Although the information of previous ocular surgeries affecting corneal endothelial cell loss (i.e., laser peripheral iridotomy and glaucoma surgery) were collected, we were not able to include the factor of previous ocular surgeries into the model due to a very low prevalence of previous ocular surgeries and no interesting outcome developed. Further study with a larger sample size is required to establish this association.

In conclusion, we demonstrated that FECD was not uncommon in Thai patients with cataracts. Performing phacoemulsification alone according to recommendations from the AAO to consider CCT at 640 microns, could be applied in Thai patients with FECD. However, the surgeon should avoid intraoperative complications to reduce risk for developing CEF. Apart from assessing pre-operative parameters, surgeons should also consider the possibility of and try to avoid any intra-operative complications, which potentially results in CEF after phacoemulsification for each individual patient. Comprehensive patient counselling prior to performing phacoemulsification alone is mandatory for patients with FECD.

\section{Acknowledgment}

We would like to thank Ms. Sranya Phaisawang for language editing and proofreading.

\section{Disclosure}

The authors declare that there is no conflicts of interest in this article.

\section{References}

1. Nanda GG, Alone DP. REVIEW: current understanding of the pathogenesis of Fuchs' endothelial corneal dystrophy. Mol Vis. 2019;25:295-310.

2. Park CY, Lee JK, Gore PK, Lim CY, Chuck RS. Keratoplasty in the United States: a 10-year review from 2005 through 2014. Ophthalmology. 2015;122(12):2432-2442. doi:10.1016/j. ophtha.2015.08.017

3. Soh YQ, Kocaba V, Pinto M, Mehta JS. Fuchs endothelial corneal dystrophy and corneal endothelial diseases: East meets West. Eye (Lond). 2020;34(3):427-441. doi:10.1038/s41433-019-0497-9

4. Ong Tone S, Kocaba V, Böhm M, Wylegala A, White TL, Jurkunas UV. Fuchs endothelial corneal dystrophy: the vicious cycle of Fuchs pathogenesis. Prog Retin Eye Res. 2021;80:100863.

5. Bourne RR, Minassian DC, Dart JK, Rosen P, Kaushal S, Wingate N. Effect of cataract surgery on the corneal endothelium: modern phacoemulsification compared with extracapsular cataract surgery. Ophthalmology. 2004;111(4):679-685. doi:10.1016/j.ophtha.2003.07.015

6. Walkow T, Anders N, Klebe S. Endothelial cell loss after phacoemulsification: relation to preoperative and intraoperative parameters. J Cataract Refract Surg. 2000;26(5):727-732. doi:10.1016/S0886-3350(99)00462-9

7. Viberg A, Byström B, Claesson Armitage M, Behndig A, Byström B. Incidence of corneal transplantation after challenging cataract surgery in patients with and without corneal guttata. J Cataract Refract Surg. 2020;46:961-966. 
8. Ventura AC, Wälti R, Böhnke M. Corneal thickness and endothelial density before and after cataract surgery. Br J Ophthalmol. 2001;85 (1):18-20. doi:10.1136/bjo.85.1.18

9. Kim YW, Kim MK, Wee WR. Long-term evaluation of endothelial cell changes in Fuchs corneal dystrophy: the influence of phacoemulsification and penetrating keratoplasty. Korean $J$ Ophthalmol. 2013;27(6):409-415. doi:10.3341/kjo.2013.27.6.409

10. Hayashi K, Yoshida M, Manabe S, Hirata A. Cataract surgery in eyes with low corneal endothelial cell density. J Cataract Refract Surg. 2011;37(8):1419-1425. doi:10.1016/j.jcrs.2011.02.025

11. Olson RJ, Braga-Mele R, Chen SH, et al. Cataract in the adult eye preferred practice pattern ${ }^{\circledR}$. Ophthalmology. 2017;124(2):P1-p119. doi:10.1016/j.ophtha.2016.09.027

12. Viberg A, Samolov B, Claesson Armitage M, Behndig A, Byström B. Incidence of corneal transplantation after phacoemulsification in patients with corneal guttata: a registry-based cohort study. $J$ Cataract Refract Surg. 2020;46(7):961-966.

13. Arnalich-Montiel F, Mingo-Botín D, De Arriba-palomero P. Preoperative risk assessment for progression to descemet membrane endothelial keratoplasty following cataract surgery in Fuchs endothelial corneal dystrophy. Am J Ophthalmol. 2019;208:76-86. doi:10.1016/j.ajo.2019.07.012

14. Patel SV, Hodge DO, Treichel EJ, Spiegel MR, Baratz KH. Predicting the prognosis of Fuchs endothelial corneal dystrophy by using scheimpflug tomography. Ophthalmology. 2020;127 (3):315-323. doi:10.1016/j.ophtha.2019.09.033

15. Adamis AP, Filatov V, Tripathi BJ, Tripathi RC. Fuchs' endothelial dystrophy of the cornea. Surv Ophthalmol. 1993;38(2):149-168. doi:10.1016/0039-6257(93)90099-S

16. Thylefors B, Chylack LT, Konyama K, et al. A simplified cataract grading system. Ophthalmic Epidemiol. 2002;9(2):83-95. doi:10.1076/opep.9.2.83.1523

17. Afshari NA, Pittard AB, Siddiqui A, Klintworth GK. Clinical study of Fuchs corneal endothelial dystrophy leading to penetrating keratoplasty: a 30-year experience. Arch Ophthalmol. 2006;124 (6):777-780. doi:10.1001/archopht.124.6.777
18. Ti SE, Chee SP. Cataract surgery in patients with Fuchs'. Ophthalmology. 2006;113(10):1883-1884. doi:10.1016/j. ophtha.2006.02.012

19. Seitzman GD, Gottsch JD, Stark WJ. Cataract surgery in patients with Fuchs' corneal dystrophy: expanding recommendations for cataract surgery without simultaneous keratoplasty. Ophthalmology. 2005;112(3):441-446. doi:10.1016/j.ophtha.2004.10.044

20. Badr M, Masis Solano M, Amoozgar B, Nguyen A, Porco T, Lin S. Central corneal thickness variances among different Asian ethnicities in glaucoma and nonglaucoma patients. J Glaucoma. 2019;28 (3):223-230. doi:10.1097/IJG.0000000000001180

21. Haseltine SJ, Pae J, Ehrlich JR, Shammas M, Radcliffe NM. Variation in corneal hysteresis and central corneal thickness among black, hispanic and white subjects. Acta Ophthalmol. 2012;90(8): e626-31. doi:10.1111/j.1755-3768.2012.02509.x

22. van Cleynenbreugel H, Remeijer L, Hillenaar T. Cataract surgery in patients with Fuchs' endothelial corneal dystrophy: when to consider a triple procedure. Ophthalmology. 2014;121(2):445-453. doi:10.1016/j.ophtha.2013.09.047

23. Liu Y, Zeng M, Liu X, et al. Torsional mode versus conventional ultrasound mode phacoemulsification: randomized comparative clinical study. J Cataract Refract Surg. 2007;33(2):287-292. doi:10.1016/j.jcrs.2006.10.044

24. Doors M, Berendschot TT, Touwslager W, Webers CA, Nuijts RM. Phacopower modulation and the risk for postoperative corneal decompensation: a randomized clinical trial. JAMA Ophthalmol. 2013;131(11):1443-1450. doi:10.1001/jamaophthalmol.2013.5009

25. Fang JP, Amesur KB, Baratz KH. Preexisting endothelial abnormalities in bilateral postoperative descemet membrane detachment. Arch Ophthalmol. 2003;121(6):903-904. doi:10.1001/archopht.121.6.903

26. Al-Mezaine HS. Descemet's membrane detachment after cataract extraction surgery. Int Ophthalmol. 2010;30(4):391-396. doi:10.1007/s10792-010-9367-y
Clinical Ophthalmology

\section{Publish your work in this journal}

Clinical Ophthalmology is an international, peer-reviewed journal covering all subspecialties within ophthalmology. Key topics include: Optometry; Visual science; Pharmacology and drug therapy in eye diseases; Basic Sciences; Primary and Secondary eye care; Patient Safety and Quality of Care Improvements. This journal is indexed on PubMed
Dovepress

Central and CAS, and is the official journal of The Society of Clinical Ophthalmology (SCO). The manuscript management system is completely online and includes a very quick and fair peer-review system, which is all easy to use. Visit http://www.dovepress.com/ testimonials.php to read real quotes from published authors. 